\title{
Transcutaneous electrical nerve stimulation produces variable changes in somatosensory evoked potentials, sensory perception and pain threshold: clinical implications for pain relief
}

\author{
JOHN F GOLDING, HEATHER ASHTON, RICHARD MARSH, JOHN W THOMPSON \\ From the Department of Pharmacological Sciences, The Medical School, University of Newcastle upon Tyne, \\ $U K$
}

SUMMARY Transcutaneous electrical nerve stimulation decreased early and late somatosensory evoked potential amplitudes and stimulus intensity ratings, and elevated sensory detection threshold, in normal subjects. Effects on pain threshold depended on pre-treatment threshold. These findings are relevant to treatment of clinical pain by transcutaneous electrical nerve stimulation.

Transcutaneous electrical nerve stimulation (TENS) and electroacupuncture are assuming increasing clinical importance as non-pharmacological methods of pain relief. The mechanisms of their analgesic action remain obscure despite many investigations, ${ }^{1-22}$ and it is not known how they affect sensory processing in general. One approach to this question has been to study the effects of these procedures on somatosensory evoked potentials (SEPs), ${ }^{172-25}$ but the results so far are confusing and sometimes contradictory. Thus in one study electroacupuncture reduced the amplitude of early SEP components ${ }^{25}$ while in others transcutaneous electrical nerve stimulation had no effect on early components ${ }^{23}$ but reduced the amplitude of late components. ${ }^{22}{ }^{23}$ It is not known whether effects on early SEPs are due to peripheral nerve refractoriness and hyperpolarisation ${ }^{25}$ or to central interference effects as produced by vibration or tactile stimulation in areas near the SEP stimulation site. ${ }^{26-30}$ Nor is it clear whether effects on late SEPs represent a general distraction of attention or some more specific, localised action. 2223

In the present study, the effect of transcutaneous electrical nerve stimulation on both early and late

Address for reprint requests: Dr JF Golding, Clinical Psychopharmacology Unit, Department of Pharmacological Sciences, The Medical School, University of Newcastle upon Tyne, Framlington Place, Newcastle upon Tyne, NE2 4HH, UK.

Received 29 October 1985 and in revised form 19 March 1986. Accepted 24 March 1986
SEP components, subjective assessment of stimulus intensity, sensory detection threshold and pain threshold were investigated. Particular attention was paid to the localisation of effects and to individual differences in response.

\section{Methods}

\section{SEP recording}

$\mathrm{Ag} / \mathrm{AgCl}$ electrodes were placed at the following sites: both mastoids, FZ' (midway between FZ and CZ), CZ, and $\mathbf{C 3}^{\prime}$ and $\mathrm{C4}^{\prime}(2 \mathrm{~cm}$ diagonally back from $\mathrm{C} 3$ and $\mathrm{C} 4)(10-20$ system). ${ }^{31}$ EEG was recorded from $\mathrm{C3}^{\prime}$ and $\mathrm{C4}^{\prime}$ to $\mathrm{FZ}^{\prime}$ reference (for short latency SEPs) and from CZ referenced to two mastoids (for late SEPs). Signals were amplified (Devices EEG pre-amplifiers, early SEPs: $T=0.3 \mathrm{~s}, \mathrm{HF}$ response flat to $5 \mathrm{kHz}$; late SEPs: T $=4 \mathrm{~s}$, HF roll off $6 \mathrm{~dB} /$ octave at 75 $\mathrm{Hz}$ ) and averaged on a PDP8E computer with fast arithmetic unit. ADC sampling rate was $8 \mathrm{kHz}$ with $62.5 \mathrm{~ms}$ window for early SEPs and $2 \mathrm{kHz}$ with $500 \mathrm{~ms}$ window for late SEPs; stimulus onset was $5 \mathrm{~ms}$ from start of sweep, amplitude resolution was 10 bits. Signals were simultaneously recorded on FM tape (Racal).

Two hundred stimuli presented unilaterally at $3 \mathrm{~Hz}$ were utilised for averaging an early SEP, 100 stimuli at $0.2 \mathrm{~Hz}$ per side (50 left interleaved with 50 right), for late SEPs, the averaged SEPs being produced by programmed sorting according to the side of stimulation. Square-wave electrical stimuli (200 $\mu$ s pulse width) were presented (Grass stimulator with constant current unit CCUIA) through two 3.5 $\mathrm{cm}^{2}$ carbon electrodes wrapped around the outside edge of first and second phalanges of each index finger (cathodes proximal). Skin conductance level (SCL) was monitored as described previously. ${ }^{32}$ 
Transcutaneous electrical nerve stimulation

Transcutaneous electrical nerve stimulation was applied unilaterally over the median nerve at the wrist through two $6.6 \mathrm{~cm}^{2}$ carbon electrodes $1.5 \mathrm{~cm}$ apart, with a flexible earth band electrode applied to the upper forearm. Stimulation frequency was $100 \mathrm{~Hz}$, pulse width $200 \mu \mathrm{s}$. Three minutes were allowed with re-adjustment of current intensity every 30 seconds to approach an initial subjective plateau before recording the first SEP during treatment and transcutaneous electrical nerve stimulation was re-adjusted between SEPs to the subjective criterion "strong but comfortable". Consequently, a gradual rise in transcutaneous electrical nerve stimulation current occurred from initiation $(9.8 \pm 4.3 \mathrm{~mA})$ to cessation $(11.9 \pm 5.6 \mathrm{~mA})$ of treatment.

The following procedure was used to provide a control with sham transcutaneous electrical nerve stimulation. In the sham transcutaneous electrical nerve stimulation group, the stimulus was applied initially as for the active treatment group. The current level was then slowly reduced to zero over $30 \mathrm{~s}$ and the subject informed: "Subjective fading of transcutaneous electrical nerve stimulation is a common phenomenon and, even if you cannot definitely feel the transcutaneous electrical nerve stimulation, it will be having an effect". At the equivalent time when transcutaneous electrical nerve stimulation was switched-off for subjects in the real transcutaneous electrical nerve stimulation group, sham stimuli subjects were informed: "I am now switching the transcutaneous electrical nerve stimulation off, although you may not feel any definite change".

\section{Sensory and pain threshold}

Sensory detection and pain thresholds for the right and left index fingers were determined with $3 \mathrm{~Hz}$ stimuli at the same stimulus pulse-width parameters and through the same electrodes used for eliciting SEPs. These thresholds were determined by the method of limits, the average being taken of six or more observations. The subject was asked to state when stimuli of increasing current intensity became noticeable (detection threshold) and "definitely" painful (pain threshold).

\section{Subjective intensity rating scales and personality questionnaires}

Subjects rated the intensity of stimuli on a $100 \mathrm{~mm}$ visual analogue rating scale in which at $0=$ imperceptible (detection threshold), $100=$ painful (pain threshold). The short-form Sensation Seeking Scale (SSS) ${ }^{\mathbf{3 3}}$ derived and adapted from Zuckerman's ${ }^{34}$ SSS version 4, and the Eysenck Personality Questionnaire (EPQ) ${ }^{35}$ were administered.

\section{Procedure}

Subjects were 26 young, healthy, male and female student volunteers $(20.5 \pm 1.3$ years of age). Each attended the laboratory for a brief familiarisation session and a subsequent recording session. Subjects sat in a temperature controlled $\left(21^{\circ} \mathrm{C}\right)$ room; communication was by two-way intercom and observation by a "one-way" window.

Following the first determination of sensory and pain thresholds, a series of stimuli was given at various intensities until the stimulus level was reported as "strong and bearable" for continuous further stimulation, that is, below pain threshold but "uncomfortable" (see "Sensory and Pain Threshold" above). This procedure was repeated for both index fingers.

With jaw and tongue relaxed, subjects fixated a dot during SEP recording. Following each SEP series they completed an intensity rating scale. During the slow alternating SEP series, subjects were requested to count silently the stimuli (the total number of stimuli was randomly varied from 100 to 105 , but only the first 100 stimuli, 50 Left and 50 Right, were used for averaging).

SEP recording followed a fixed 15 min cycle: 200 stimuli to left index finger, subjective rating, 200 stimuli to right index finger, subjective rating, 100 slow stimuli presented to left and right index fingers alternately, subjective ratings. Five cycles were completed; two cycles before transcutaneous electrical nerve stimulation, two during the stimuli and one following cessation of the stimuli. Thresholds were determined before the first cycle, after the fourth cycle with transcutaneous electrical nerve stimulation still switched on, and finally following the fifth cycle. The side of transcutaneous electrical nerve stimulation treatment (left

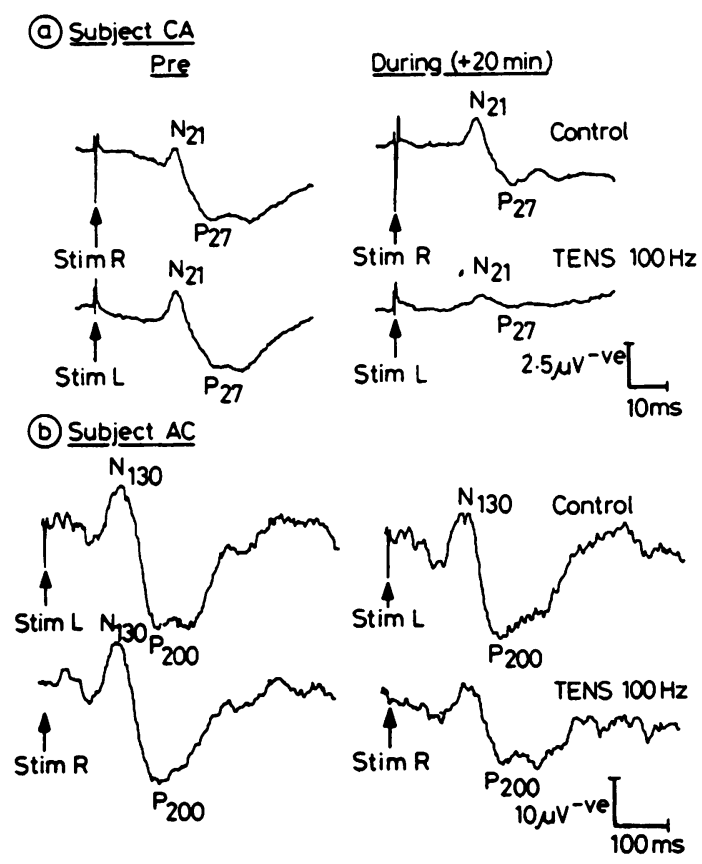

Fig 1 (a) Typical short latency SEPs elicited by shock stimuli (average of 200 trials per trace) to right and left index fingers, recorded from contralateral parietal projection areas (stimulus artefact is smaller on the side with earth band). The subject (C.A.) shows marked unilateral diminution of early SEP by TENS. (b) Typical long latency SEPs elicited by shock stimuli (average of 50 trials per trace) to right and left index fingers, recorded from the vertex (stimulus artefact is smaller on the side with earth band). The subject (A.C.) shows mainly unilateral diminution during TENS. 
Transcutaneous electrical nerve stimulation produces variable changes in somatosensory evoked potentials 1399

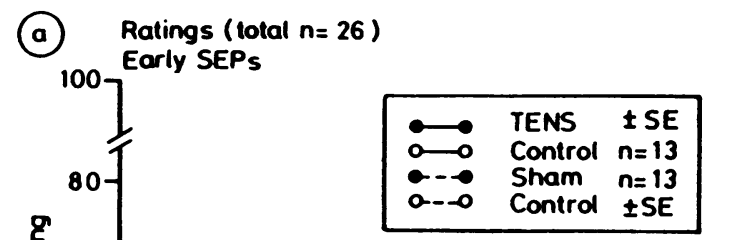

the time windows 100 to 160 and 160 to $260 \mathrm{~ms}$ respectively and the peak to peak amplitude N130-P200 $(\mu \mathrm{V})$ scored. Other components were too variable to identify reliably across all subjects.

An additional SEP measure was calculated (by computer from data on magnetic disc). This was Root Mean Square (RMS), ${ }^{36}$ the square root of the mean of the squared devi-
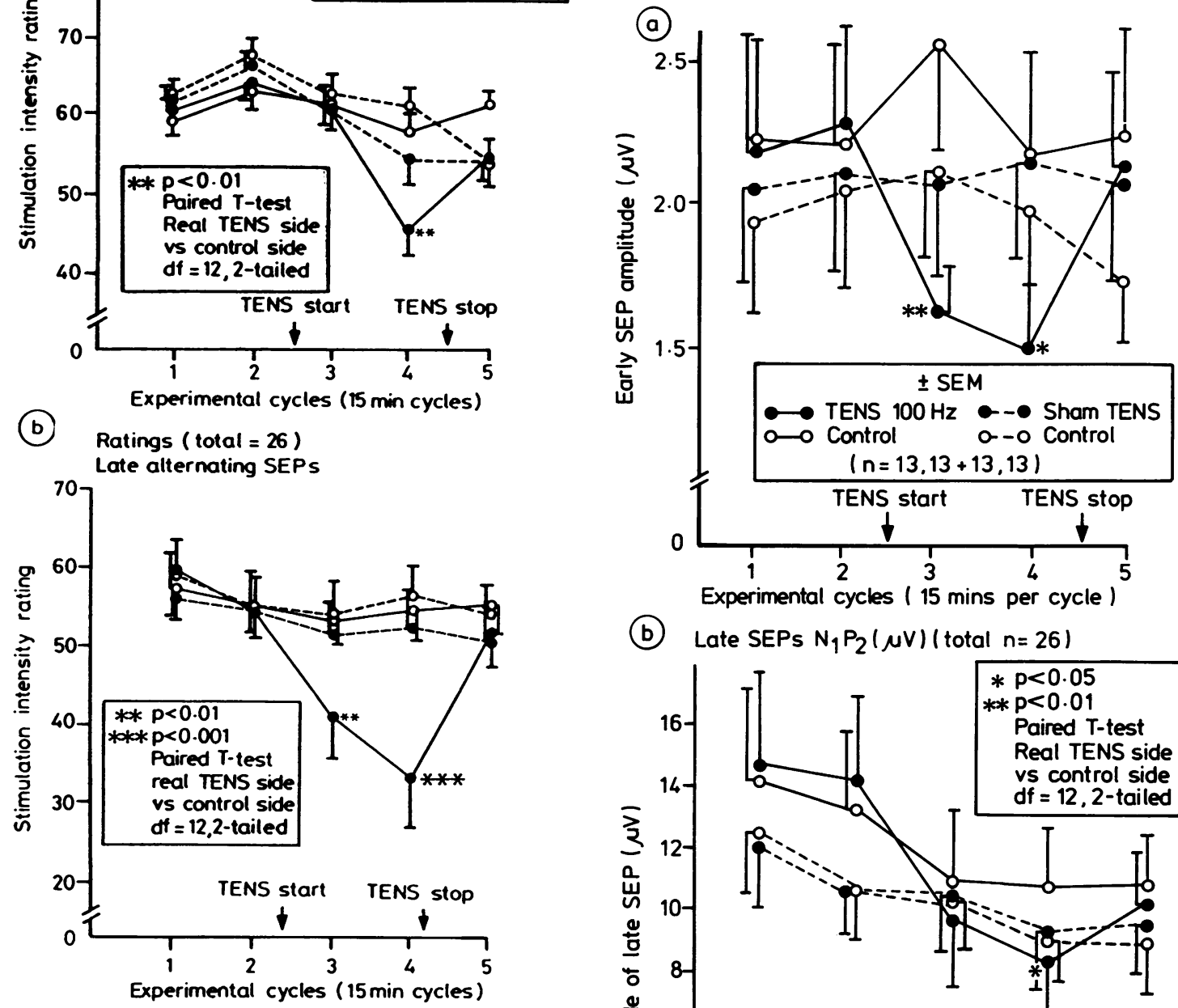

Fig 2 Subjective intensity ratings over time and by side and by group, of stimuli used in eliciting early SEPs (a) and late SEPs (b).

versus right) was randomised between subjects. Sexes were approximately balanced for side of treatment and for group ("real" versus "sham").

\section{Data analysis}

For short latency SEPs, the amplitude of the two most consistent components, N21 and P27 (fig 1), was scored in $\mu \mathrm{V}$ as peak maximum (negative) to peak (minimum). For late SEPs, the components N130 and P200 were identified in 
Table 1 Mean ( $\pm S D)$ values of subjective intensity ratings and SEP amplitude for the 5 experimental cycles, recorded on 2 sides in 2 groups of subjects, Real or Sham TENS was applied during the 3rd and 4th cycles

\begin{tabular}{|c|c|c|c|c|c|c|}
\hline Cycle & & lst & $2 n d$ & $3 r d$ & $4 t h$ & 5 th \\
\hline \multicolumn{7}{|c|}{$\begin{array}{l}\text { Subjective intensity ratings for early } \\
\text { SEPs (scale units 0-100) }\end{array}$} \\
\hline $\begin{array}{c}\text { Real TENS } \\
(n=13) \\
\text { Sham TENS } \\
(n=13)\end{array}$ & $\begin{array}{l}\text { TENS side } \\
\text { Control side } \\
\text { TENS side } \\
\text { Control side }\end{array}$ & $\begin{array}{l}60.9 \pm 9.1 \\
59.0 \pm 11 \cdot 1 \\
61.4 \pm 16.1 \\
62.6 \pm 13.9\end{array}$ & $\begin{array}{l}64.2 \pm 11.3 \\
63.5 \pm 13.7 \\
66.1 \pm 14.5 \\
67.8 \pm 15.6\end{array}$ & $\begin{array}{l}61 \cdot 2 \pm 17 \cdot 4 \\
61 \cdot 8 \pm 16 \cdot 5 \\
60 \cdot 8 \pm 16 \cdot 4 \\
63.0 \pm 17.0\end{array}$ & $\begin{array}{l}45.8 \pm 24.0 \\
58.8 \pm 11.7 \\
54.7 \pm 22.4 \\
61.8 \pm 14.7\end{array}$ & $\begin{array}{l}55.0 \pm 17.4 \\
61.6 \pm 12.0 \\
54.4 \pm 16.1 \\
54.2 \pm 17.2\end{array}$ \\
\hline \multicolumn{7}{|c|}{$\begin{array}{l}\text { Subjective intensity ratings for late } \\
\text { SEPs (scale units } 0-100 \text { ) }\end{array}$} \\
\hline $\begin{array}{c}\text { Real TENS } \\
(n=13) \\
\text { Sham TENS } \\
(n=13) \\
\text { Early SEP am }\end{array}$ & $\begin{array}{l}\text { TENS side } \\
\text { Control side } \\
\text { TENS side } \\
\text { Control side } \\
\text { des }(\mu \mathrm{V})\end{array}$ & $\begin{array}{l}59.5 \pm 10.3 \\
57.2 \pm 15.1 \\
56.0 \pm 13.7 \\
59.3 \pm 13.8\end{array}$ & $\begin{array}{l}54.5 \pm 11.3 \\
54.8 \pm 12.7 \\
54.6 \pm 13.1 \\
55.2 \pm 14.8\end{array}$ & $\begin{array}{l}41 \cdot 2 \pm 20.7 \\
58.2 \pm 9.8 \\
52.0 \pm 13 \cdot 7 \\
54.3 \pm 14.0\end{array}$ & $\begin{array}{l}33.5 \pm 21.9 \\
55.1 \pm 15.9 \\
52.8 \pm 16.5 \\
56.8 \pm 13.9\end{array}$ & $\begin{array}{l}52.4 \pm 16.1 \\
55.7 \pm 15.5 \\
50.8 \pm 16.1 \\
54.8 \pm 15.4\end{array}$ \\
\hline $\begin{array}{c}\text { Real TENS } \\
(\mathrm{n}=13) \\
\text { Sham TENS } \\
(\mathrm{n}=13) \\
\text { Late SEP amp }\end{array}$ & $\begin{array}{l}\text { TENS side } \\
\text { Control side } \\
\text { TENS side } \\
\text { Control side } \\
\text { es }(\mu \mathrm{V})\end{array}$ & $\begin{array}{l}2.19 \pm 1.22 \\
2.23 \pm 1.27 \\
2.05 \pm 1.11 \\
1.95 \pm 1.19\end{array}$ & $\begin{array}{l}2.28 \pm 1.22 \\
2.21 \pm 1.23 \\
2.10 \pm 1.19 \\
2.05 \pm 1.21\end{array}$ & $\begin{array}{l}1.64 \pm 0.59 \\
2.55 \pm 1.32 \\
2.07 \pm 1.11 \\
2.11 \pm 1.04\end{array}$ & $\begin{array}{l}1.51 \pm 0.74 \\
2.18 \pm 1.28 \\
2.15 \pm 1.21 \\
1.98 \pm 1.04\end{array}$ & $\begin{array}{l}2.13 \pm 1.21 \\
2.24 \pm 1.42 \\
2.07 \pm 1.29 \\
1.73 \pm 0.76\end{array}$ \\
\hline $\begin{array}{c}\text { Real TENS } \\
(\mathrm{n}=13) \\
\text { Sham TENS } \\
(\mathrm{n}=13)\end{array}$ & $\begin{array}{l}\text { TENS side } \\
\text { Control side } \\
\text { TENS side } \\
\text { Control side }\end{array}$ & $\begin{array}{l}14.6 \pm 10.6 \\
14.1 \pm 10.9 \\
12.0 \pm 6.4 \\
12.4 \pm 6.3\end{array}$ & $\begin{array}{l}14 \cdot 1 \pm 9.8 \\
13.2 \pm 8.7 \\
10.6 \pm 5.1 \\
10.6 \pm 5.6\end{array}$ & $\begin{array}{r}9.7 \pm 8.2 \\
10.9 \pm 9.5 \\
10.4 \pm 6.0 \\
10.2 \pm 5.3\end{array}$ & $\begin{array}{r}8.4 \pm 6.8 \\
10.7 \pm 7.7 \\
9.3 \pm 6.0 \\
9.0 \pm 4.3\end{array}$ & $\begin{array}{r}10.2 \pm 5.8 \\
10.8 \pm 7.4 \\
9.5 \pm 5.6 \\
9.0 \pm 5.1\end{array}$ \\
\hline
\end{tabular}

ation of the waveform from the baseline as calculated from the mean of all data points lying between the time windows: 35 to $250 \mathrm{~ms}$ and 35 to $500 \mathrm{~ms}$ (the results are in units where RMS $\mu \mathrm{V}=16$ units). In order to reduce any high frequency bias, the traces were automatically subjected to five passes of 3-point smoothing before RMS analysis.

\section{Results}

\section{Personality Scores}

Mean \pm SD personality scores were similar to Student norms ${ }^{33} 35$ (SS $=7.0 \pm 7 \cdot 7, \mathrm{P}=4.8 \pm 2.9$, $\mathrm{E}=16.2 \pm 3 \cdot 7, \mathrm{~N}=10.1 \pm 5.9, \mathrm{~L}=3.5 \pm 1.9$ ) although Sensation-Seeking (SS), Psychoticism (P) and Extraversion (E) scores were on the higher side of the range.

\section{Statistical analysis}

Analysis of variance for repeated measures (BMDP2V) was carried out on all data, where: "group" refers to the two groups "Real transcutaneous electrical nerve stimulation" and "Sham transcutaneous electrical nerve stimulation"; "side" refers to the two sides "transcutaneous electrical nerve stimulation side" and "control side"; "time" refers to the five repeated experimental cycles except in the case of detection and pain thresholds where only three sets of measurements were taken, pre-, during, post-transcutaneous electrical nerve stimulation. The probabilities for within-subject effects and interactions are conservative Greenhouse-Geisser corrected values, (that is, reduced for possible inflation by repeated measures, noted as "GG-corr" where relevant.
Correlations (Pearson) between sides and for cycle 1 with cycle 2 were high, confirming that the measures were consistent between side and reliable upon re-test.

\section{Early SEPS}

Early SEPs were recorded over the contralateral projection area of the hand being stimulated, that is, $\mathrm{C3}^{\prime}$ for right hand finger stimulation and $\mathrm{C4}^{\prime}$ for left hand finger stimulation. Typical traces are shown in fig 1a. ANOVA for N21P27 amplitude showed no significant main effects for group, side or time. There were marginal interactions for side $\times$ group $(F=3 \cdot 8$, $\mathrm{df}=1,24,0.05<\mathrm{p}<0.10)$ and time $\times$ group $(\mathrm{F}=2 \cdot 4, \mathrm{df}=4,96,0.05<\mathrm{p}<0 \cdot 10, \mathrm{GG}$-corr). The interactions for side $\times$ time $(F=5 \cdot 8, \mathrm{df}=4,96, \mathrm{p}<$ 0.01, GG-corr) and side $\times$ time $\times$ group $(F=3.7$, $\mathrm{df}=4,96, \mathrm{p}<0.05$, GG-corr) were significant. Examination of the means (table 1, fig 3a) indicated that the source of these interactions was a considerable fall in amplitude of early SEPs elicited from the hand being treated with real transcutaneous electrical nerve stimulation, during the application of real stimuli, and a transient increase in amplitude of early SEP elicited by stimulation of the control side in this group. This transient rise (third experimental cycle, see fig 3a) was not only significant compared to the real transcutaneous electrical nerve stimulation treatment side but also compared to the preceding pre-treatment control side SEP amplitude (paired $t=2 \cdot 42$, df $=12$; two-tailed $\mathrm{p}<0.05$ ).

\section{Late SEPS}

Typical long latency SEPs (vertex recorded) are 
shown in fig 1b. ANOVA for N130P200 amplitude of late SEPs showed a highly significant main effect for time $(\mathrm{F}=13 \cdot 4, \mathrm{df}=4,96, \mathrm{p}<0.00001$, GG-corr $)$, but no significant main effects for groups or side. There were no significant interactions for side $x$ group, time $\times$ group or side $\times$ time. However the side $\times$ time $\times$ group interaction was marginally significant $(F=2 \cdot 4, \mathrm{df}=4,96,0 \cdot 05<\mathrm{p}<0 \cdot 10$, GGcorr). In order to define this effect more clearly, the ANOVA was repeated using the mean data for the two pre-treatment and two during-treatment cycles. As before, the effect for time was highly significant $(\mathrm{F}=32 \cdot 4, \mathrm{df}=1,24, \mathrm{p}<0.00001)$ and the effects for side, for group, for side $\times$ group and for side $\times$ time non-significant. However the interactions for time $x$

(a) Root meon square (RMS) $35-250 \mathrm{~ms}$ ( Total No of subjects $=26$ )

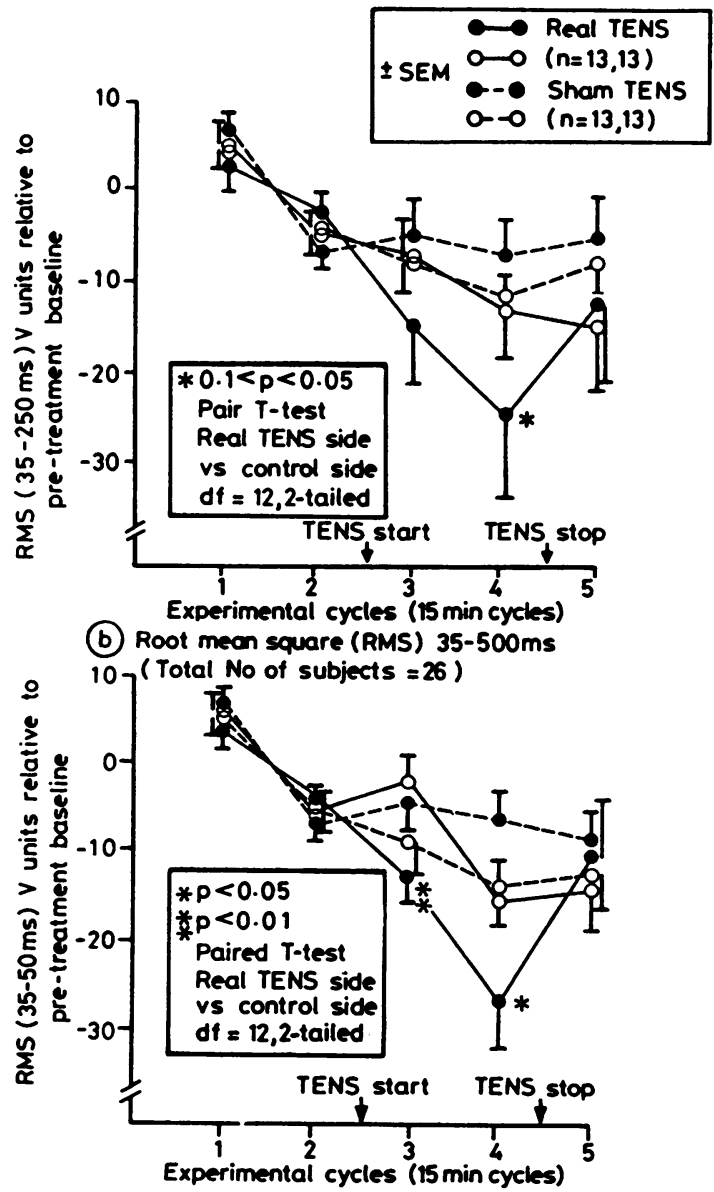

Fig 4 Root Mean Square (RMS) amplitudes of SEPs over time and by side and by group for RMS time window 35-250 $\mathrm{ms}$ (a) and RMS time window 35-500 ms. (b). group were significant $(\mathrm{F}=5 \cdot 3, \mathrm{df}=1,24, \mathrm{p}<0.05)$ and side $\times$ time $\times$ group $(F=6 \cdot 8, d f=1,24, p<$ 0.05 ). These significant effects and interactions suggested, from examination of the means (fig $3 \mathrm{~b}$, table 1), that real transcutaneous electrical nerve stimulation produced a reduction in the late SEP amplitude during treatment, that was greatest for late SEPs elicited from the hand receiving transcutaneous electrical nerve stimulation treatment but with some reduction of late SEPs elicited from the control side as well. The general time-related reduction in N130P200 SEP amplitude over the course of the five experimental cycles perhaps reflected habituation to the eliciting stimuli.

\section{Calculated SEP measures}

Changes in the root mean square (RMS) measures of the SEP are plotted in fig 4. ANOVA of RMS (35-250ms) revealed significant effects only for time $(\mathrm{F}=10.2, \mathrm{df}=4,96, \mathrm{p}<0.001, \mathrm{GG}$-corr $)$ and a marginal interaction for side $\times$ time $\times$ group $(F=2 \cdot 2$, $\mathrm{df}=4,96,0 \cdot 10>0.05$, GG-corr). Consideration of the means indicated that the time-related effect was due to a decline in RMS over the five experimental cycles. The marginally significant side $x$ time $\times$ group effect was due to the relative decline in RMS on the side with real transcutaneous electrical nerve stimulation, during real transcutaneous electrical nerve stimulation, followed by a recovery on switching-off real transcutaneous electrical nerve stimulation.

ANOVA of RMS (35-500 ms) produced significant effects for time $(F=24.9$, df $=4,96, p<0.00001$, GG-corr), for side $\times$ group $(F=4.9, \mathrm{df}=1,24, \mathrm{p}<$ $0.05)$ and for side $\times$ time $\times$ group $(F=3.8$, $\mathrm{df}=4,96, \mathrm{p}<0.01$, GG-corr). Effects for group and side $\times$ time were non-significant. The time $\times$ group interaction just failed significance after application of Greenhouse-Geisser correction. Consideration of the means indicated that these significant effects and interactions were due to an overall time-related decline in RMS (35-500 ms) and a reduction of SEPs elicited from the hand treated with real transcutaneous electrical nerve stimulation, during the application of real transcutaneous electrical nerve stimulation.

\section{SEP latencies}

Mean latencies of SEP components were as follows: $\mathrm{N} 21: 21 \cdot 3 \pm 1.0 \mathrm{~ms}, \mathrm{P} 27: 27 \cdot 6 \pm 2.7 \mathrm{~ms}$, N130: $125 \cdot 0$ $\pm 28.7 \mathrm{~ms}$, P200: $212.4 \pm 55.3 \mathrm{~ms}$. ANOVA of latencies of early and late SEP components revealed no significant main effects or interactions.

Subjective intensity ratings

ANOVA for subjective intensity ratings of stimuli for 
Table 2 Detection and pain thresholds $(m A)( \pm S D)$ by time and treatment group $(n=13,13$ Real; $n=13,13$ Sham)

\begin{tabular}{|c|c|c|c|c|}
\hline Time period & & Pre & During & Post \\
\hline \multicolumn{5}{|l|}{ Detection thresholds (mA) } \\
\hline Real TENS & $\begin{array}{l}\text { TENS side } \\
\text { Control side }\end{array}$ & $\begin{array}{l}3.0 \pm 1.8 \\
3.1 \pm 1.8\end{array}$ & $\begin{array}{l}6.1 \pm 3.0 \\
3.5 \pm 1.5\end{array}$ & $\begin{array}{l}3.9 \pm 1.5 \\
3.2 \pm 1.8\end{array}$ \\
\hline Sham TENS & $\begin{array}{l}\text { TENS side } \\
\text { Control side }\end{array}$ & $\begin{array}{l}3.5 \pm 1.8 \\
3.1 \pm 1.9\end{array}$ & $\begin{array}{l}4.0 \pm 2.3 \\
3.6 \pm 2.6\end{array}$ & $\begin{array}{l}4.6 \pm 2.8 \\
3.9 \pm 2.7\end{array}$ \\
\hline \multirow{2}{*}{$\begin{array}{l}\text { Pain thresholds (mA) } \\
\text { Real TENS }\end{array}$} & & & & \\
\hline & $\begin{array}{l}\text { TENS side } \\
\text { Control side }\end{array}$ & $\begin{array}{l}15.2 \pm 5.5 \\
14.5 \pm 4.1\end{array}$ & $\begin{array}{l}16.9 \pm 3.8 \\
15.7 \pm 2.5\end{array}$ & $\begin{array}{l}16.3 \pm 3.7 \\
15.8 \pm 2.2\end{array}$ \\
\hline Sham TENS & $\begin{array}{l}\text { TENS side } \\
\text { Control side }\end{array}$ & $\begin{array}{l}17 \cdot 1 \pm 5.6 \\
16 \cdot 2 \pm 6.3\end{array}$ & $\begin{array}{l}19.2 \pm 4.8 \\
18.1 \pm 6.4\end{array}$ & $\begin{array}{l}20.2 \pm 5.2 \\
18.6 \pm 6.5\end{array}$ \\
\hline
\end{tabular}

early SEPs produced a highly significant main effect for time $(F=6 \cdot 5, \mathrm{df}=4,96, \mathrm{p}<0.001, \mathrm{GG}$-corr $)$, a marginal effect for side $(\mathrm{F}=3.7, \mathrm{df}=1,24,0.05<\mathrm{p}$ $<0 \cdot 10)$ and no significant effect for group. The interaction for side $\times$ time was significant $(F=4 \cdot 0$, $\mathrm{df}=4,96, \mathrm{p}<0.05, \mathrm{GG}$-corr) but interactions for side $\times$ group, for time $\times$ group and time $\times$ group $\times$ side were non-significant. Examination of means (table 1) indicated that these effects were due to small time-related changes in subjective intensity rating, although these were not systematic enough to term them habituation and a (marginal) tendency for the intensity of stimuli to be rated as less on the treatment side following real- or sham-transcutaneous electrical nerve stimulation. The lowest mean intensity rating was on the hand treated with real transcutaneous electrical nerve stimulation during application of transcutaneous electrical nerve stimulation and, when tested separately, this achieved significance (4th experimental cycle, fig $2 a$ ).

The ANOVA for subjective intensity ratings of stimuli used to elicit late SEPs produced a series of significant effects. The main effects and interactions, for time $(F=4.0, \mathrm{df}=4,96, \mathrm{p}<0.05$, GG-corr $)$, side $(\mathrm{F}=12 \cdot 1, \mathrm{df}=1,24, \mathrm{p}<0 \cdot 01)$, side $\times$ time $(\mathrm{F}=10.3, \mathrm{df}=4,96, \mathrm{p}<0.001, \mathrm{GG}$-corr $)$, side $\times$ time $\times$ group $(F=8 \cdot 6, \mathrm{df}=4,96, \mathrm{p}<0.001, \mathrm{GG}-$ corr) were significant, although the interactions for time $\times$ group and side $\times$ group were non-significant. Examinations of means (table 1, fig 2b) indicated that although there was a small tendency for the stimuli to be rated as less intense over the five successive experimental cycles, the source of the highly significant interactions was the large reduction in subjective intensity of the stimuli on the real-transcutaneous electrical nerve stimulation treated hand during transcutaneous electrical nerve stimulation application.

Skin conductance level ( $S C L$ )

ANOVA for SCL data (in log $\mu$ mhos) over the five experimental cycles plus the initial pre-SEP stimulation baseline showed no significant effects for transcutaneous electrical nerve stimulation and for brevity the data are not presented.
Sensory detection threshold

ANOVA of sensory detection threshold revealed no significant effects for group and side $\times$ group interactions. However, significant effects occurred for time $(\mathrm{F}=13.2, \mathrm{df}=2,48, \mathrm{p}<0.00001, \mathrm{GG}-\mathrm{corr})$, for time $\times$ group $(F=7.5, \mathrm{df}=2,48, \mathrm{p}<0.01, \mathrm{GG}-$ corr $)$, for time $\times$ side $(F=9.7, d f=2,48, p<0.001$,

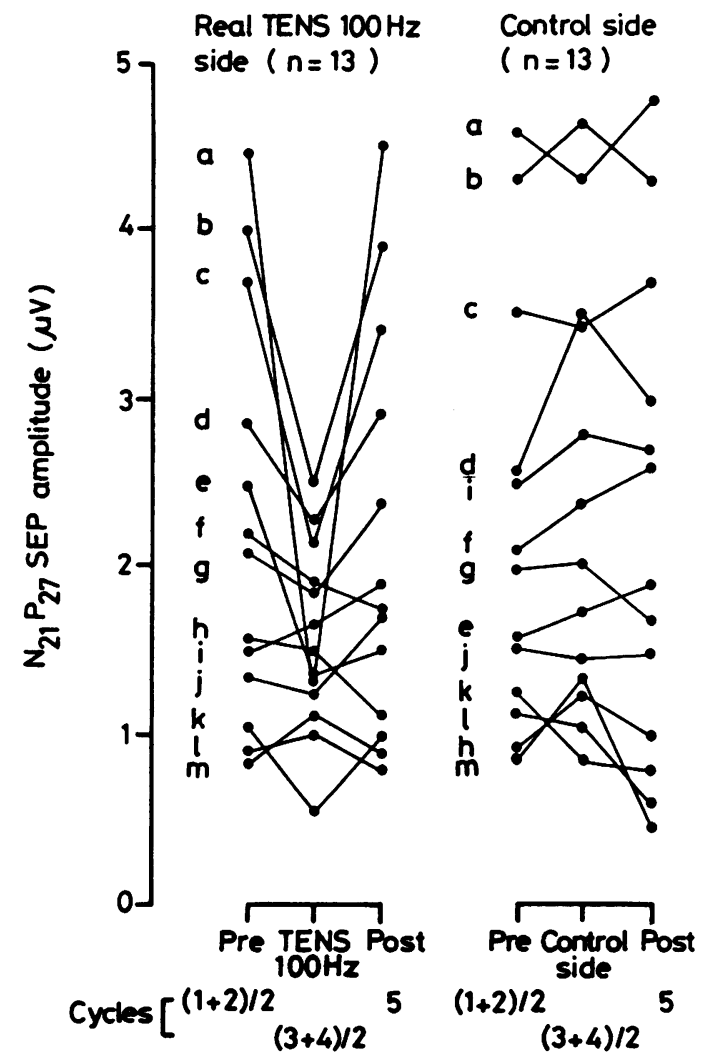

Fig 5 Individual differences in response to real TENS of the early SEP N21P27. Lower case letters identify individual subjects' responses from side with TENS at $100 \mathrm{~Hz}$ and from corresponding opposite control side. 


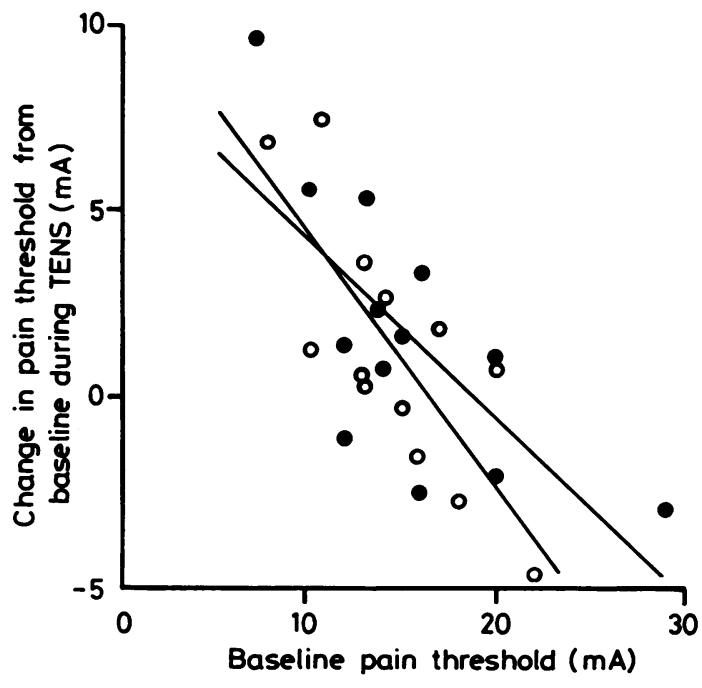

Fig 6 Relationship between baseline pain threshold (pre-TENS) and change in pain threshold (during TENS minus baseline) for subjects treated with real TENS. Filled circles: side of TENS application; open circles: control side, very similar regression lines are shown for both sides.

$(r=-0 \cdot 73,-0 \cdot 79$, TENS and control sides respectively; $p$ $<0.01, d f=11,2$-tailed for both).

GG-corr $)$ and for time $\times$ side $\times$ group $(F=9 \cdot 5$, $\mathrm{df}=2,48, \mathrm{p}<0.0001, \mathrm{GG}$-corr). Examination of the means (table 2) indicated that the source of these effects was the tendency for detection threshold to increase slightly over time in all groups and, more importantly, the large rise in detection threshold on the hand treated with real transcutaneous electrical nerve stimulation during transcutaneous electrical nerve stimulation application.

\section{Pain threshold}

ANOVA of pain threshold showed no significant interactions or main effects apart from a significant effect of time $(F=7.5, \mathrm{df}=2,48, \mathrm{p}<0.01$, GGcorr). The source of this effect was the increase over time of pain threshold in both groups (table 2). Although transcutaneous electrical nerve stimulation did not alter mean pain threshold, there was a significant correlation between initial pain threshold and transcutaneous electrical nerve stimulation effect (see below: Correlations).

\section{Correlations}

There was a striking positive correlation between pretreatment SEP amplitude and magnitude of real transcutaneous electrical nerve stimulation-induced reduction of the SEP. This applied to both early and late SEPs (baseline $\times$ real transcutaneous electrical nerve stımulation-induced reduction, for early SEPs, $\mathrm{r}=+0.88, \mathrm{df}=11, \mathrm{p}<0.001$; for late SEPs, $r=+0.80, \mathrm{df}=11, \mathrm{p}<0.001,2$-tailed). Individual differences in early SEP magnitude are illustrated in fig 5 .

There was also a highly significant and systematic relationship between baseline pain threshold and response to transcutaneous electrical nerve stimulation (fig 6). Individuals with low baseline pain thresholds showed increases in pain threshold during transcutaneous electrical nerve stimulation, whereas individuals with high baseline pain thresholds showed small decreases. This relationship was most marked for the real transcutaneous electrical nerve stimulation group but was not localised with respect to side of treatment. The baseline pain threshold $\times$ change in pain threshold correlations were: real transcutaneous electrical nerve stimulation hand $r=-0.73, p<0.01$, control hand $r=-0.79, p<$ 0.01 ; sham transcutaneous electrical nerve stimulation hand $\mathrm{r}=-0.58, \mathrm{p}<0.05$, control hand $\mathrm{r}=-0 \cdot 23, \mathrm{p}=\mathrm{ns} ; 2$-tailed, $\mathrm{df}=11$ in all cases.

Finally, a number of other interrelationships, although non-significant, indicated that real transcutaneous electrical nerve stimulation-induced elevation of detection threshold covaried with reduction of early SEP $(r=0.46, d f=11, p=N S)$ but not with reduction of late $\operatorname{SEP}(r=-0.09, \mathrm{df}=11$, $\mathrm{p}=\mathrm{NS}$ ). Greater real transcutaneous electrical nerve stimulation-induced reduction in late SEP magnitude correlated non-significantly with greater reduction in self-rated intensity of the stimuli $(r=0 \cdot 31, \mathrm{df}=11$, $\mathrm{p}=\mathrm{NS})$. Thus, subjective report and objective measurement (SEP) showed parallel changes, both in terms of mean changes as a function of treatment and in terms of the correlations reported above.

\section{Discussion}

This investigation showed that transcutaneous electrical nerve stimulation produced a significant reduction in amplitude of both early and late components of the SEP and that the changes were localised, being largely confined to SEPs generated from the hand treated with real transcutaneous electrical nerve stimulation. These findings differ from those reported by Francini et $a^{23}$ who found no effect of $50 \mathrm{~Hz}$ transcutaneous electrical nerve stimulation on early SEPs but a generalised, bilateral reduction in late SEP amplitude. These authors suggested that the effects were due to a disrupting effect of transcutaneous electrical nerve stimulation on general sensory integration/attentional mechanisms. Such general mechanisms are unlikely to explain the present results since the effects were localised and the early components, which are less susceptible to changes in 
attention, ${ }^{37}$ were affected as well as the late components. It is possible that the relatively intense, "uncomfortable", nature of the stimuli and the control of the subject's attention by requiring them to count the stimuli may have reduced generalised effects on the attentional process in the present study.

With regard to the early SEP, there is evidence that, for electrical stimulation of the hand, the initial scalprecorded negative component with a post-stimulus latency around $20 \mathrm{~ms}$ (N21 in the present study) signifies the first cortical representation of afferent activity. ${ }^{38}{ }^{39}$ Mean peripheral conduction velocity for electrical stimulation of the hand is $71 \mathrm{~m} / \mathrm{s},{ }^{40}$ indicating that such information is carried in fast $\mathrm{A}$ beta afferents. ${ }^{41}$ Late SEP components, with a latency between 100 and $300 \mathrm{~ms}$ (N130 P200 in the present study) probably represent the subsequent cortical processing of information from $A$ beta and $A$ delta fibres. ${ }^{42}$ The observed, mainly unilateral, diminution in early and late SEPs by transcutaneous electrical nerve stimulation therefore suggests that the procedure disrupted, at some point during its passage to the cortex, the sensory information conveyed from $A$ beta and A delta fibres.

The site of this action does not appear to be peripheral since, in separate experiments on a few subjects, recordings of evoked potentials from nerve at the elbow produced by electrical stimulation of the finger showed no attenuation during application of transcutaneous electrical nerve stimulation. The effects could have been due to changes at spinal, subcortical or cortical levels or to a combination of changes at several levels of neural organisation. Transcutaneous electrical nerve stimulation also produced some effects on SEP responses elicited from the non-treated (control) side, notably a transient increase in early SEP amplitude and a slight reduction in late SEPs (figs $3 a, b, 4 a, b)$. These results show that there is no simple one-to-one relationship between early and late SEPs and suggest that transcutaneous electrical nerve stimulation may exert several actions simultaneously or initiate a chain of secondary events.

Concomitant with the effects on SEPs there was a significant reduction in subjective rating of stimulus intensity and an elevation of sensory detection threshold. Both changes were confined to the hand treated with real transcutaneous electrical nerve stimulation. These findings are consistent with the SEP changes indicating disruption of afferent information initiated by $A$ beta and $A$ delta fibre activity. Although the stimuli used in the present study were not definitely painful, they were assessed as "uncomfortable" and the parallel reduction of both ratings and SEP amplitudes suggests that transcutaneous electrical nerve stimulation may have interfered with sensory input of an aversive as well as a purely tactile nature.
In addition, transcutaneous electrical nerve stimulation produced a biphasic effect on pain threshold, increasing it if the initial threshold was low and decreasing it if it was high. Francini $e a^{23}$ found a similar biphasic effect of $50 \mathrm{~Hz}$ transcutaneous electrical nerve stimulation, depending on initial pain threshold. In both studies the effects of transcutaneous electrical nerve stimulation on pain threshold were not localised to the side of treatment but were demonstrable on the opposite side. These findings, like the SEP effects, suggest a central action of transcutaneous electrical nerve stimulation. In like fashion, several psychotropic drugs have been shown to produce biphasic effects on brain activity in man, the direction of effect depending on starting state. ${ }^{4344}$

Marked individual differences in the various responses to transcutaneous electrical nerve stimulation were observed in the present study. The relation between initial pain threshold and pain threshold response to transcutaneous electrical nerve stimulation, and the positive correlation between pretreatment SEP amplitude and transcutaneous electrical nerve stimulation-induced reduction of both early and late SEP amplitudes, suggest that both initial pain threshold and pre-treatment SEP amplitude may reflect possibly linked factors which determine response to transcutaneous electrical nerve stimulation. Such relationships may have important clinical implications since equally marked individual differences in the analgesic response to transcutaneous electrical nerve stimulation occur in patients with pain. ${ }^{3-54546}$ For example, patients described by Mann ${ }^{46}$ as "strong reactors" to acupuncture may correspond to experimental subjects with large SEPs and low pain thresholds who are most sensitive to transcutaneous electrical nerve stimulation. This possibility opens new avenues of investigation into variation of treatment response among patients with chronic pain.

The authors thank Mrs VE Wright and Mrs M Cheek for secretarial and data processing assistance. This work was supported in part by MRC grant number G8108158N, current grant support: Wellcome Trust.

\section{References}

1 Thorsteinsson G, Stonnington HH, Stillwell GK, Elveback LR. The placebo effect of transcutaneous electrical stimulation. Pain 1978;5:31-41.

2 Ashton CH, Ebenezer I, Golding JF, Thompson JW. Effects of acupuncture and transcutaneous electrical nerve stimulation on cold-induced pain in normal subjects. J Psychosomatic Res 1984;28:301-8.

3 Johansson F, Almay BGL, von Knorring L. Personality factors related to the outcome of treatment with trans- 
cutaneous nerve stimulation. Psychiatria Clin North Am 1981;14:96-104.

4 Johansson F, Almay BGL, von Knorring L, Terenius L. Predictors for the outcome of treatment with high frequency transcutaneous electrical nerve stimulation in patients with chronic pain. Pain 1980;9:55-61.

5 Linzer M, Long DM. Transcutaneous neural stimulation for relief of pain. IEEE Trans Biomed Engng 1976;23:341-5.

6 Hyodo M, Kitade T, Hosaka E. Study on the enhanced analgesic effect induced by phenylalanine during acupuncture analgesia in humans. In: Bonica $\mathrm{JJ}$, ed. Advances in Pain Research and Therapy vol 5, New York: Raven Press, 1983:577-82.

7 Hallin RG. Human pain mechanisms studied with percutaneous microneurography. In: (ed B Bromm) Pain Measurement in Man. Neurophysiological Correlates of Pain. Amsterdam: Elsevier, 1984:39-53.

8 Torebjork HE, Hallin RG. Responses in human A and C fibres to repeated electrical intradermal stimulation. J Neurol Neurosurg Psychiatry 1974;37:653-64.

9 Campbell JN, Taub A. Local analgesia from percutaneous electrical stimulation: A peripheral mechanism. Arch Neurol 1973;28:347-50.

10 Ignelzi RJ, Nyquist JK. Direct effect of electrical stimulation on peripheral nerve evoked activity: implications in pain relief. $J$ Neurosurg 1976;45:159-65.

11 Swett JE, Law JD. Analgesia with peripheral nerve stimulation: absence of a peripheral mechanism. Pain 1983;15:55-70.

12 Wall PD. The gate control theory of pain mechanisms. Brain 1978;101:1-18.

13 Mayer DJ, Watkins LR. Role of endorphins in endogenous pain control systems. In: Ban TA, Pichot $\mathbf{P}$, Poldinger W, eds. Modern Problems of Pharmacology vol 17, Basel: New York: S Karger, 1981:68-96.

14 Melzack R, Wall PD. Pain mechanisms: a new theory. Science 1965;150:971.

15 Sjolund BH, Eriksson MBE. The influence of naloxone on analgesia produced by peripheral conditioning stimulation. Brain Res 1979;173:295-302.

16 Sjolund $\mathrm{BH}$, Terenius L, Eriksson MBE. Increased cerebrospinal fluid levels of endorphins after electroacupuncture. Acta Physiol Scand 1977;100:382-4.

17 Chapman CR, Benedetti C, Butler SH. Cerebral response measures of stimulation-induced and opiateinduced dental analgesia in man: attempted analgesia reversal with narcotic antagonist. In: Anderson D, Matthews B, eds. Pain in the Trigeminal Region. Elsevier/North Holland Biomedical Press 1977: 423-33.

18 Chapman CR, Benedetti C, Colpitts YH, Gerlach R. Naloxone fails to reverse pain thresholds elevated by acupuncture: Acupuncture analgesia reconsidered. Pain 1983;16:13-31.

19 Kang Bao'e, Zhou Zhongfu, Han Jisheng. The involvement of serotinergic transmission in periaqueductal grey for electroacupuncture analgesia and morphine analgesia in rabbits. Kexue Tongbao 1984;29:116-22.

20 Han JS, Terenius L. Neurochemical basis of acupuncture analgesia. Ann Rev Pharmacol Toxicol 1982;22: 193-220.
21 Cheng RSS, Pomeranz B. A combined treatment with D-amino acids and electroacupuncture produces a greater analgesia than either treatment alone; Naloxone reverses these effects. Pain 1980;8:231-6.

22 Ashton CH, Golding JF, Marsh VR, Thompson JW. The effects of transcutaneous electrical nerve stimulation and aspirin on late somatosensory evoked potentials in normal subjects. Pain 1984;18:377-86.

23 Francini F, Maresca M, Procacci P, Zoppi M. Relationship between somatosensory evoked potential components and cutaneous pain threshold: effects of transcutaneous electrical nerve stimulation. In: Courjon J, Mauguiere F, Revol M, eds. Clinical Applications of Evoked Potentials in Neurology. New York: Raven Press, 1982:384-8.

24 Satran R, Goldstein MN. Pain perception; modification of threshold of intolerance and cortical potentials by cutaneous stimulation. Science 1973;180:1201-2.

25 Yamauchi N, Asahara S, Sato T, Fujitani Y, Oikawa T. Effects of electrical acupuncture on human somatosensory evoked potentials. Yonago Acta Medica 1976;20:158-66.

26 Abbruzzese $\mathbf{G}$, Abbruzzese $\mathbf{M}$, Favale $\mathrm{E}$, Ivaldi $\mathbf{M}$, Leandri $M$, Ratto $S$. The effect of hand muscle vibration on the somatosensory evoked potential in man: an interaction between lemniscal and spinocerebellar inputs? $J$ Neurol Neurosurg Psychiatry 1980;43:433-7.

27 Giblin DR. Somatosensory evoked potentials in healthy subjects and in patients with lesions of the nervous system. Ann NY Acad Sci 1964;112:93-142.

28 Jones SJ. An 'Interference' approach to the study of somatosensory evoked potentials in man. Electroencephalogr Clin Neurophysiol 1981;52:517-30.

29 Stowell $\mathrm{H}$. Event related brain potentials from somatosensory nociceptive stimulation. In: Crue BL, ed. Chronic Pain. New York: Spectrum, 1979:105-36.

30 Kakigi R, Jones SJ. Effects on median nerve SEPs of tactile stimulation applied to adjacent and remote areas of the body surface. Electroencephalogr Clin Neurophysiol 1985;62:252-65.

31 Jasper $\mathrm{HH}$. The 10-20 electrode system of the International Federation. Electroencephalogr Clin Neurophysiol 1958;10:371-5.

32 Golding JF, Mangan GL. Arousing and de-arousing effects of cigarette smoking under conditions of stress and mild sensory isolation. Psychophysiology 1982; 19:449-56.

33 Golding JF, Harpur T, Brent-Smith H. Personality, drinking and drug-taking correlates of cigarette smoking. Person Individ Diff 1983;4:371-80.

34 Zuckerman M. Sensation Seeking: Beyond the Optimal Level of Arousal. Lawrence Erlbaum, Hillsdale NJ, (Distributed by Wiley, New York).

35 Eysenck HJ, Eysenck SBG. Manual of the Eysenck Personality Questionnaire (Junior \& Adult). London: Hodder \& Stoughton 1975.

36 Buchsbaum M. Self-regulation of stimulus intensity: Augmenting/reducing and averaged evoked response. In: Schwartz GE, Shapiro D, eds. Consciousness \& Self-Regulation. Advances in Research Vol I. New York: Plenum Press, 1976:101-35.

37 Desmedt JE. Cognitive component in cerebral event- 
related potentials and selective attention. In: Desmedt JE, ed. Progr Clin Neurophysiol Vol 6 Basel: Karger, 1979.

38 Goff WR, Rosner BS, Allison T. Distribution of cerebral somatosensory evoked responses in normal man. Electroencephalogr Clin Neurophysiol 1962;6:697-713.

39 Suzuki I, Mayanagi Y. Intracranial recording of short latency somatosensory evoked potentials in man: identification of origin of each component. Electroencephalogr Clin Neurophysiol 1984;59:286-96.

40 Desmedt JE, Cheron G. Prevertebral (oesophageal) recording of subcortical somatosensory evoked potentials in man: the spinal P13 component and the dual nature of the spinal generators. Electroencephalogr Clin Neurophysiol 1981;52:257-75.

41 Swett JE, Bourassa CM. Electrical stimulation of peripheral nerve. In: Patterson MM, Kerner RP eds. Electrical Stimulation Research Techniques. New York: Academic Press, 1981:243-95.

42 Bromm B. Pain-related components in the cerebral potential, experimental and multivariate statistical approaches. In: Bromm B, ed. Pain Measurement in Man. Neurophysiological Correlates of Pain. Amsterdam: Elsevier, 1984:257-90.

43 Ashton H, Golding J, Marsh VR, Millman JE, Thompson JW. The seed and the soil: effect of dosage, personality and starting state on the response to delta-9tetrahydrocannabinol in man. $\mathrm{Br} J$ Clin Pharmacol 1981;10:579-89.

44 Ashton H, Millman JE, Telford R, Thompson JW. A comparison of some physiological and psychological effects of propranolol and diazepam in normal subjects. Br J Clin Pharmacol 1976;3:551-9.

45 Thompson JW. Pain: Mechanisms and principles of management In: Grimley Evans J, Caird FI, eds. Advanced Geriatric Medicine. Vol 4 London: Pitmans, 1984:3-16.

46 Mann F. Scientific Aspects of Acupuncture, 2nd ed London: William Heinemann Medical Books, 1983. 